DOI 10.37882/2223-2966.2020.10.28

\title{
МЕТОДИКА ОПРЕДЕЛЕНИЯ ПРОЕКТНЫХ ПАРАМЕТРОВ ЦЕНТРОБЕЖНОГО ВОЗДУШНОГО КОМПРЕССОРА НА ОСНОВЕ МАТЕМАТИЧЕСКОЙ МОДЕЛИ БЕЗОТБОРНОЙ СИСТЕМЫ КОНДИЦИОНИРОВАНИЯ ВОЗДУХА
}

\begin{abstract}
METHOD FOR DETERMINING THE DESIGN PARAMETERS OF A CENTRIFUGAL AIR COMPRESSOR BASED ON A MATHEMATICAL MODEL OF A NONSELECTIVE AIR CONDITIONING SYSTEM
\end{abstract}

\section{Smagin K. Starostin R. Savelyev \\ K. Napreenko N. Vasiliev Ye.Krasavin}

Summary: The article considers a mathematical model of an air conditioning system for a promising medium-haul aircraft. The key feature of this system is the use of an electric centrifugal air compressor as a source of compressed air. The methodology for determining the design parameters of an air compressor based on the results of modeling the air conditioning system in several modes is shown.

Keywords: mathematical model, air conditioning system, centrifugal compressor, air cooling unit, air cycle, compression-evaporation cycle.
Смагин Денис Игоревич

Начальник лаборатории, Московский авиационный институт (национальный исследовательский университет)

79637587781@yandex.ru

Старостин Константин Игоревич

Ведущий инженер, Московский авиационный институт (национальный исследовательский университет) ki-star1969@yandex.ru

Савельев Роман Сергеевич

Ведущий инженер, Московский авиационный институт (национальный исследовательский университет) r_sr@inbox.ru

Напреенко Константин Сергеевич Инженер 2 категории, Московский авиационный институт (национальный исследовательский университет) konaprko@yandex.ru

Васильев Николай Георгиевич Техник, Московский авиационный институт (национальный исследовательский университет) col.vasilie2012@yandex.ru

Красавин Егор Эдуардович Техник, Московский авиационный институт (национальный исследовательский университет) krasavin.ieghor@mail.ru

Аннотация: В статье рассмотрена математическая модель системы кондиционирования воздуха для перспективного среднемагистрального самолёта. Ключевой особенностью данной системы является использование электроприводного центробежного воздушного компрессора в качестве источника сжатого воздуха. Показана методология определения проектных параметров воздушного компрессора по результатам моделирования системы кондиционирования на нескольких режимах.

Ключевые слова: математическая модель, система кондиционирования воздуха, центробежный компрессор, установка охлаждения воздуха, воздушный цикл, компрессионно-испарительный цикл.

противообледенительной системы (ПОС). Эти системы будут работать за счет электрогенераторов и аккумуляторов. В частности, электроэнергия будет подаваться на центробежный компрессор, который будет подавать воздух для СКВ.

На данный момент есть 2 возможных варианта исполнения установки охлаждения воздуха (УОВ): классический - установка охлаждения с воздушным циклом (УОВ с применением турбохолодильника), перспективная 
- установка охлаждения с компрессионно-испарительным циклом (парокомпрессионная УОВ).

Системы подачи воздуха аналогичны для двух вариантов СКВ без отбора воздуха от двигателей и представляют собой электроприводной центробежный воздушный компрессор. Структура и состав системы распределения воздуха так же аналогичны [2] [3].

Установка охлаждения воздушного цикла (ВЦ) включает в себя:

- Теплообменники воздуховоздушные (первичный и вторичный);

- Схему влагоотделения в линии высокого давления (теплообменник-подогреватель, теплообменник-конденсатор, влагоотделитель);

- Турбохолодильник с одной ступенью турбины;

- Запорно-регулирующие устройства.

- Установка охлаждения компрессионно-испарительного цикла (ПКМ) включает в себя:

- Теплообменник испаритель (воздух-фреон);

- Теплообменник пре-конденсатор (фреон-воздух);

- Теплообменник конденсатор (фреон-топливо);

- Компрессор двухступенчатый фреоновый;

- Запорно-регулирующие устройства.

Таким образом, в настоящей статье рассматривается возможность применения СКВ без отбора воздуха от двигателя, расчет потребной характеристики центробежного компрессора, сравнение двух вариантов исполнения УОВ и нахождение потребной электрической мощности для электромотора.

\section{Методология расчета}

В качестве рассматриваемой СКВ была взята система из двух независимых линий с двумя центробежными компрессорами. Рассматриваемая схема работает в трех режимах: земля, переходный, крейсер, которые дают представление о условиях атмосферы за бортом самолета и необходимых условиях внутри гермокабины, которые должна обеспечивать СКВ. Параметры атмосферы за бортом и внутри гермокабины приведены в Таблице 1. Эти же параметры будут входными в компрессоры. Также система работает в 4 режимах нагрузки: минимальный (min), средний (med), максимальный (max) и форсированный (force). Каждый из режимов нагрузок представляет собой моделирование следующих ситуаций: min - обеспечение минимального потребного расхода подаваемого воздуха на трех режимах работы, med - обеспечение нормального расхода подаваемого воздуха на трех режимах работы, max - обеспечение максимального расхода воздуха на режимах максимальных тепло и холодопроизводительности (режимы работы земля и переходный), force - обеспечение минимального расхода воздуха при отказе одного из двух центробежных компрессоров (оставшийся компрессор работает на две подсистемы(режим работы крейсерский)).

Таблица 1.

Режимы работы

\begin{tabular}{|l|c|c|c|}
\hline \multicolumn{1}{|c|}{ Режим } & $\mathrm{TBX}^{\circ}{ }^{\circ} \mathrm{C}$ & Рвх, Па & Ркаб, Па \\
\hline Земля & 20 & 101300 & 101300 \\
\hline Переходный & 12 & 98082 & 83000 \\
\hline Крейсерский & -44 & 34248 & 83000 \\
\hline
\end{tabular}

Расход является определяющей величиной. Поэтому характеристика центробежного компрессора определяется через потребные расходы (Таблица 2).

Таблица 2.

Потребные расходы

\begin{tabular}{|c|c|}
\hline Режим нагрузки & $\mathrm{G}, \mathrm{K} г / \mathrm{4}$ \\
\hline Min & 1500 \\
\hline Med & 1900 \\
\hline Max & 2400 \\
\hline Force & 3000 \\
\hline
\end{tabular}

В свою очередь, каждый из режимов нагрузок определяет перепад давлений на следующих элементах: система подачи воздуха (СПВ), УОВ, канал. Перепад давлений на УОВ зависит от потребного расхода $G$ и удельной холодопроизводительности УОВ. В свою очередь, удельная холодопроизводительность тоже зависит от потребного расхода и вычисляется по следующей формуле:

$$
q=\frac{Q}{G}
$$

где:

$q$ - удельная холодопроизводительность УОВ, Дж/кг;

$Q$ - полная холодопроизводительность УОВ, Дж/с;

$G$ - потребный расход, кг/с.

Практический холодильный коэффициент характеризует степень термодинамической эффективности реального цикла авиационной воздушно-холодильной машины с точки зрения энергетического баланса (первое начало термодинамики).

Также из-за рассмотрения двух типов УОВ перепады давлений на них будут отличаться. Результаты перепадов давлений в зависимости от режимов работы и режимов нагрузок представлены в Таблице 3.

Таблица 3.

\begin{tabular}{|c|c|c|c|c|}
\hline \multicolumn{5}{|c|}{ Режимы нагрузок } \\
\hline \multicolumn{5}{|c|}{ УОВ турбохолодильник } \\
\hline $\begin{array}{c}\text { Режим } \\
\text { нагрузки }\end{array}$ & $\begin{array}{l}\text { Режим } \\
\text { работы }\end{array}$ & $\triangle \mathrm{P} C П \mathrm{~B}$, Па & $\triangle \mathrm{P}$ УОВ, Па & $\begin{array}{c}\Delta \text { P каналы, } \\
\text { Па }\end{array}$ \\
\hline \multirow{3}{*}{ Min } & Земля & 20006 & 120132 & 5006 \\
\hline & Переходный & 20012 & 120186 & 5013 \\
\hline & Крейсерский & 20018 & 120203 & 5027 \\
\hline
\end{tabular}




\begin{tabular}{|c|c|c|l|c|}
\multicolumn{5}{|c|}{ УОВ турбохолодильник } \\
\hline $\begin{array}{c}\text { Режим } \\
\text { нагрузки }\end{array}$ & $\begin{array}{c}\text { Режим } \\
\text { работы }\end{array}$ & $\Delta \mathrm{P} \mathrm{CПВ,} \mathrm{Па}$ & $\Delta \mathrm{P}$ уОВ, Па & $\begin{array}{c}\Delta \mathrm{P} \text { каналы, } \\
\text { Па }\end{array}$ \\
\hline \multirow{3}{*}{ Med } & Земля & 20010 & 170157 & 5009 \\
\cline { 2 - 5 } & Переходный & 20015 & 170193 & 5018 \\
\cline { 2 - 5 } & Крейсерский & 20021 & 170214 & 5030 \\
\hline \multirow{2}{*}{ Max } & Земля & 20013 & 210182 & 5012 \\
\cline { 2 - 5 } & Переходный & 20019 & 210231 & 5036 \\
\hline Force & Крейсерский & 22026 & 177618 & 5045 \\
\hline
\end{tabular}

\begin{tabular}{|c|c|c|l|c|}
\hline \multicolumn{5}{|c}{ УОВ парокомпрессионная } \\
\hline $\begin{array}{c}\text { Режим } \\
\text { нагрузки }\end{array}$ & $\begin{array}{c}\text { Режим } \\
\text { работы }\end{array}$ & $\Delta \mathrm{P}$ СПВ, Па & $\Delta$ Р УОВ, Па & $\begin{array}{c}\Delta \text { к каналы, } \\
\text { Па }\end{array}$ \\
\hline \multirow{3}{*}{ Min } & Земля & 20005 & 13001 & 5003 \\
\cline { 2 - 5 } & Переходный & 20011 & 13009 & 5010 \\
\cline { 2 - 5 } & Крейсерский & 20015 & 13018 & 5023 \\
\hline \multirow{3}{*}{ Med } & Земля & 20008 & 15006 & 5004 \\
\cline { 2 - 5 } & Переходный & 20012 & 15017 & 5014 \\
\cline { 2 - 5 } & Крейсерский & 20019 & 15022 & 5026 \\
\hline \multirow{2}{*}{ Max } & Земля & 20011 & 17010 & 5016 \\
\cline { 2 - 5 } & Переходный & 20019 & 17019 & 5032 \\
\hline \multirow{2}{*}{ Forсе } & Крейсерский & 40023 & 26028 & 10015 \\
\hline
\end{tabular}

\section{Математическая моцель СКВ без отбора от силовой установки}

Данная схема была смоделирована в программе LMS Amesim (Рисунок 1). В данной схеме красным цветом выделена горячая линия, синим - холодная, желтым - линия после смешения воздуха, черным - блоки управления. В

данной модели было сделано следующее допущение: в электромотор поступает заранее преобразованный трехфазный переменный ток.

Таблица 4.

\section{Суммарные перепады давлений}

\begin{tabular}{|c|c|c|}
\multicolumn{3}{|c|}{ УОВ турбохолодильник } \\
\hline \multirow{2}{*}{ Режим нагрузки } & Режим работы & РВых, Па \\
\hline \multirow{3}{*}{ Min } & Земля & 246444 \\
\cline { 2 - 3 } & Переходный & 228211 \\
\cline { 2 - 3 } & Крейсерский & 228248 \\
\hline \multirow{3}{*}{ Med } & Земля & 296476 \\
\cline { 2 - 3 } & Переходный & 278226 \\
\cline { 2 - 3 } & Крейсерский & 278265 \\
\hline \multirow{2}{*}{ Max } & Земля & 336507 \\
\hline \multirow{2}{*}{ Force } & Переходный & 318286 \\
\hline
\end{tabular}

\begin{tabular}{|c|c|c|}
\hline \multicolumn{3}{|c|}{ УОВ парокомпрессионная } \\
\hline \multirow{2}{*}{ Режим нагрузки } & Режим работы & Рвых, Па \\
\hline \multirow{3}{*}{ Min } & Земля & 139309 \\
\cline { 2 - 3 } & Переходный & 121030 \\
\cline { 2 - 3 } & Крейсерский & 121056 \\
\hline \multirow{3}{*}{ Med } & Земля & 141318 \\
\cline { 2 - 3 } & Переходный & 123043 \\
\cline { 2 - 3 } & Крейсерский & 123067 \\
\hline \multirow{2}{*}{ Max } & Земля & 143337 \\
\cline { 2 - 3 } & Переходный & 125070 \\
\hline \multirow{2}{*}{ Force } & Крейсерский & 159066 \\
\hline
\end{tabular}

Потребное давление на выходе из центробежных

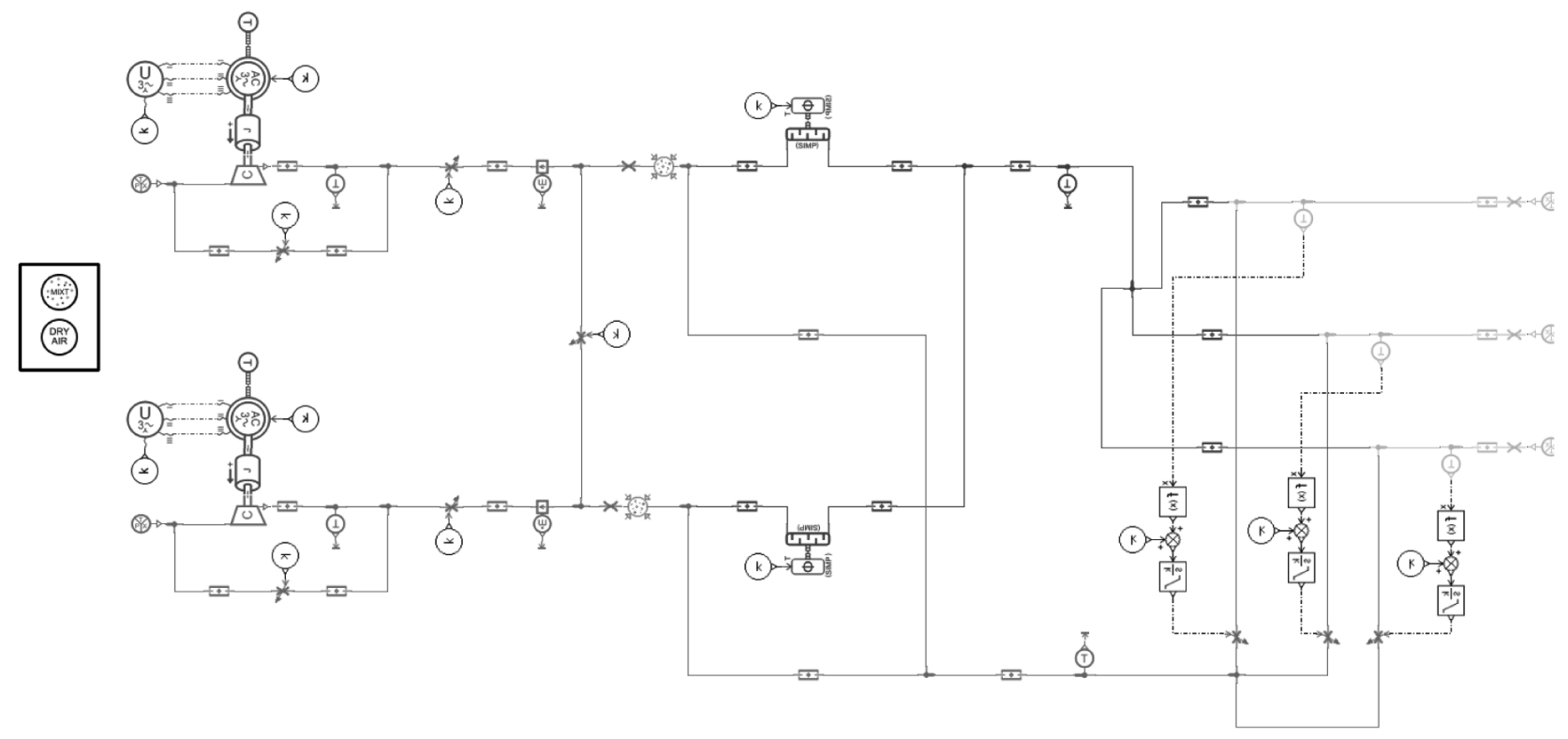

Рис. 1. Принципиальная схема в LMS Amesim 
компрессоров можно представить как сумму всех перепадов давлений и давления в кабине (Рвых). Из вышесказанного следует, что суммарный перепад давления будет разным для турбохолодильной установки охлаждения и парокомпрессионной. Результаты вычислений приведены в Таблице 4.

Помимо этого, производится сравнительный анализ 2 типов УОВ: классический (турбохолодильник) и перспективный (парокомпрессионная холодильная машина).

Благодаря вышеуказанным данным, можно узнать степени сжатий для каждого режима и вида нагрузки установки охлаждения воздуха, которые вычисляются по следующей формуле:

$$
\pi_{\mathrm{K}}=\frac{P_{\mathrm{Bgx}}}{P_{\mathrm{Bx}}}
$$

где:

$\pi \kappa$ - степень повышения давления в компрессоре,

Рвых - давление на выходе из компрессора,

Рвх - давление на входе в компрессор.

Результаты вычислений степеней сжатия для каждого режима работы и нагрузок приведены в Таблице 5.

\section{Степени сжатия}

\begin{tabular}{|c|c|c|}
\hline \multicolumn{3}{|c|}{ УОВ турбохолодильник } \\
\hline \multirow{2}{*}{ Режим нагрузки } & Режим работы & пк \\
\hline \multirow{3}{*}{ Min } & Земля & 2,4 \\
\cline { 2 - 3 } & Переходный & 2,3 \\
\cline { 2 - 3 } & Крейсерский & 6,6 \\
\hline \multirow{3}{*}{ Med } & Земля & 2,9 \\
\cline { 2 - 3 } & Переходный & 2,8 \\
\cline { 2 - 3 } & Крейсерский & 8,1 \\
\hline \multirow{2}{*}{ Max } & Земля & 3,3 \\
\hline \multirow{2}{*}{ Force } & Переходный & 3,2 \\
\hline
\end{tabular}

\begin{tabular}{|c|c|c|}
\hline \multirow{3}{*}{ УОВ парокомпрессионная } \\
\hline \multirow{2}{*}{ Режим нагрузки } & Режим работы & тк \\
\hline \multirow{3}{*}{ Min } & Земля & 1,3 \\
\cline { 2 - 3 } & Переходный & 1,2 \\
\cline { 2 - 3 } & Крейсерский & 3,5 \\
\hline \multirow{3}{*}{ Med } & Земля & 1,4 \\
\cline { 2 - 3 } & Переходный & 1,2 \\
\cline { 2 - 3 } & Крейсерский & 3,6 \\
\hline \multirow{2}{*}{ Max } & Земля & 1,4 \\
\hline \multirow{2}{*}{ Force } & Переходный & 1,2 \\
\hline
\end{tabular}

Количество потребных оборотов зависит от входных параметров воздуха, которые зависят от режима работы, режимов нагрузок и потребного расхода, которое можно определить по следующей формуле:

$$
N=\frac{G}{\rho\left(P_{\mathrm{EX}}, T_{\mathrm{BX}}\right) L},
$$

где:

$N$ - количество потребных оборотов, об/мин;

$G$ - потребный расход воздуха, кг/ч;

$\rho\left(P_{8 x}, T_{b x}\right)$ - плотность воздуха на входе в компрессор в зависимости от давления и температуры воздуха, кг/м3;

$L$ - перепускная способность центробежного компрессора л/об.

Результаты вычислений потребных оборотов показаны в Таблице 6.

Таблица 6.

Потребные обороты компрессора

\begin{tabular}{|c|c|c|}
\hline \multirow{2}{*}{ Режим нагрузки } & Режим работы & $\mathrm{N}, 06 /$ мин \\
\hline \multirow{2}{*}{ Min } & Земля & 7175 \\
\cline { 2 - 3 } & Переходный & 7410 \\
\cline { 2 - 3 } & Крейсерский & 21230 \\
\hline \multirow{3}{*}{ Med } & Земля & 9090 \\
\cline { 2 - 3 } & Переходный & 9385 \\
\cline { 2 - 3 } & Крейсерский & 26880 \\
\hline \multirow{2}{*}{ Max } & Земля & 11480 \\
\hline \multirow{2}{*}{ Force } & Переходный & 11857 \\
\hline
\end{tabular}

На основании полученных данных можно построить необходимую характеристику компрессора. На рисунке 2 показана характеристика предположительного центробежного компрессора, где красной линией показаны минимально допустимые значения компрессора при УОВ в варианте турбохолодильника, розовой - реальные значения компрессора при УОВ в варианте турбохолодильника, область между этими двумя кривыми - зона регулирования компрессора; черной линией показаны минимально допустимые значения компрессора при УОВ в варианте парокомпрессионной холодильной машины, синей - реальные значения компрессора при УОВ в варианте парокомпрессионной холодильной машины, область между этими двумя кривыми - зона регулирования компрессора.

Затем были получены значения выходной механической мощности электродвигателя в зависимости от режима работы и нагрузки (Таблица 7): 


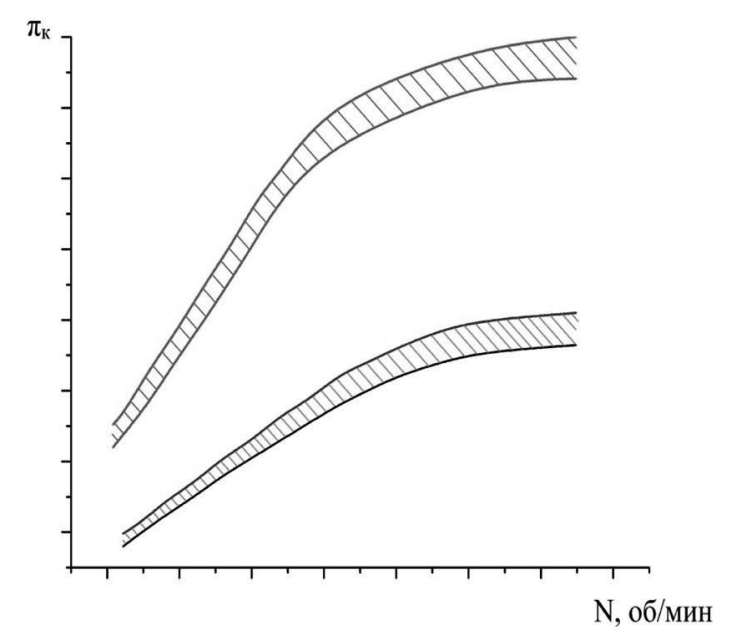

Рис. 2. Характеристика компрессора

Таблица 7.

Выходящая механическая мощность электромотора

\begin{tabular}{|c|c|c|}
\hline Режим нагрузки & Режим работы & Р, кВт \\
\hline \multirow{2}{*}{ Min } & Земля & 19.77 \\
\cline { 2 - 3 } & Переходный & 22.318 \\
\cline { 2 - 3 } & Крейсерский & 122.24 \\
\hline \multirow{3}{*}{ Med } & Земля & 29.332 \\
\cline { 2 - 3 } & Переходный & 36.694 \\
\cline { 2 - 3 } & Крейсерский & 165.642 \\
\hline \multirow{2}{*}{ Max } & Земля & 41.888 \\
\hline \multirow{2}{*}{ Force } & Переходный & 41.891 \\
\hline \multirow{2}{*}{} & Крейсерский & 342.674 \\
\hline
\end{tabular}

Затем, на основании полученных данных, можно найти действующее значение переменного тока по следующей формуле:

$$
I_{r m s}=\frac{P}{3 * U_{r m s}}
$$

где:

Irms - действующее значение силы тока, А;

$P$ - выходящая механическая мощность электромотора, кBт;

Urms - среднеквадратичное напряжение, B.

Результаты вычислений приведены в таблице 8.

После этого можно найти значения полной мощности для каждого режима работы и нагрузки по следующей формуле:

$$
S_{a p p}=3 * U_{r m s} * I_{r m s},
$$

где:

Sapp - полная мощность, кВт;

Urms - среднеквадратичное напряжение, B;

Irms - действующее значение силы тока, А.

Результаты вычислений приведены в таблице 9.

Таблица 8.

Действующее значение силы тока

\begin{tabular}{|c|c|c|}
\hline \multirow{2}{*}{ Режим нагрузки } & Режим работы & Irms, A \\
\hline \multirow{2}{*}{ Min } & Земля & 57.302 \\
\cline { 2 - 3 } & Переходный & 64.689 \\
\cline { 2 - 3 } & Крейсерский & 354.32 \\
\hline \multirow{3}{*}{ Med } & Земля & 85.021 \\
\cline { 2 - 3 } & Переходный & 106.36 \\
\cline { 2 - 3 } & Крейсерский & 480.122 \\
\hline \multirow{2}{*}{ Max } & Земля & 121.416 \\
\cline { 2 - 3 } & Переходный & 121.422 \\
\hline \multirow{2}{*}{ Force } & Крейсерский & 993.258 \\
\hline
\end{tabular}

Таблица 9.

Полная мощность электромотора

\begin{tabular}{|c|c|c|}
\hline \multirow{2}{*}{ Режим нагрузки } & Режим работы & Sарр, кВт \\
\hline \multirow{2}{*}{ Min } & Земля & 19.77 \\
\cline { 2 - 3 } & Переходный & 22.318 \\
\cline { 2 - 3 } & Крейсерский & 122.24 \\
\hline \multirow{3}{*}{ Med } & Земля & 29.332 \\
\cline { 2 - 3 } & Переходный & 36.694 \\
\cline { 2 - 3 } & Крейсерский & 165.642 \\
\hline \multirow{2}{*}{ Max } & Земля & 41.888 \\
\hline \multirow{2}{*}{ Force } & Переходный & 41.891 \\
\hline
\end{tabular}

\section{Зак^ючение}

Таким образом, благодаря программе LMS Amesim есть возможность создания математической модели безотборной системы кондиционирования воздуха с достаточной степенью точности с учетом как электрической части, так и воздушной.

Анализируя полученные данные, можно сказать, что наиболее нагруженным режимом является форсированный режим нагрузки. Поэтому, при проектировании реальной системы электропитания нужно уделить особое внимание этому режиму нагрузки и защитить электрическую цепь соответствующим образом.

Также следует учесть, что чем выше число оборотов, тем выше уровень шума и вибраций, производимого компрессором. 
Однако данная схема была смоделирована в первом приближении, поэтому для увеличения точности вычисления нужно увеличить количество задаваемых переменных. Помимо этого, в ходе дальнейшего уточнения стоит проанализировать выбор размерности компрессора.

Кроме этого, из графиков видно, что потребные ха- рактеристики компрессора при использовании парокомпрессионной УОВ ниже, чем при использовании турбохолодильника. Поэтому выбор УОВ в исполнении парокомпрессионной холодильной машины является более предпочтительным, чем УОВ в исполнении турбохолодильника.

\section{ЛИТЕРАТУРА}

1. Innovation process. Model Stage-Gate Idea-to-launch. Stage-gate system Standard. URL: http://stage-gate.com

2. Cronin M.J. Design aspect of systems in all electric aircraft (SAE Techn. Pap. Ser.), 821436. DOl: https://doi.org/10.4271/821436.

3. Воронович С., Каргапольцев В., Кутахов В. Полностью электрический самолет // Авиапанорама. 2009. № 2. С. 23-27.

4. Матвеенко А.М. Системы оборудования летательных аппаратов. М.: Машиностроение, 2005. 558 с.

5. Варгафтик Н.Б. Справочник по теплофизическим свойствам газов и жидкостей. 2-е изд., М.: Наука, 1972.721 с.

6. Бретшнайдер С. Свойства газов и жидкостей. Инженерные методы расчета. Ленинград: Химия, 1966. 536 с.

7. Идельчик И.Е. Справочник по гидравлическим сопротивлениям. 3-е изд. М.: Машиностроение, 1992.672 с.

8. Смагин Д.И., Савельев Р.И. Методы разработки современных бортовых систем перспективного самолета // 0бзор конференции «10 Международная конференция по машиностроению и аэрокосмической технике».

9. Смагин Д.И., Притулкин А.А. Формирование концепта перспективного самолета использующего альтернативные топлива и источники энергии // 0бзор конференции “Гагаринские чтения - 2018".

10. Pekka Roytta. Study of a vapor-compression air-conditioning system for jetliners. Lappeenrannan teknillinen yliopisto Digipaino.

11. ECS for the All Electric Aircraft Fabienne COUAILLAC MSc. AVD 2006-2007.

12. Каллиопин А.К., Савельев Р.С., Смагин Д.И. Основные тенденции развития систем кондиционирования воздуха перспективных летательных аппаратов // Инженерный журнал: наука и инновации. 2017, Вып. 6.

13. Сатин А.А, Савельев Р.С. Моделирование авиационных систем кондиционирования воздуха пассажирских самолетов в программном комплексе Simintech // Computational nanotechnology. 2018. № 3. C. 24-31.

14. Каллиопин А.К. Математическое моделирование авиационных систем кондиционирования воздуха. М.: МАИ, 1992. 77 с.

15. Антонова Н.В., Дубровин Л.Д, Егоров Е.Е. Проектирование авиационных систем кондиционирования воздуха. М.: Машиностроение, 2006. 384 с.

16. Гарганеев А.Г., Харитонов С.А. Технико-экономические оценки создания самолета с полностью электрифицированным оборудованием // Доклады ТУсур. 2009. № 2. С. 179-184.

17. Ian Moir, Allan Seabridge. Aircraft Systems: Mechanical, electrical, and avionics subsystems integration, third edition. John Wiley \& Sons, Ltd., 2008.

18. Шустров Ю.М., Булаевский М.М. Авиационные системы кондиционирования воздуха. М.: Машиностроение, 1978. 160 с.

19. Voronovich S., Kargapoltsev V., Kutakhov V. All electric aircraft. Air panorama. 2009. № 2. Pp. $23-27$.

20. Medic G., Sharma O.P., Jongwook L., Hardin L.W., McCormick D.C., Cousins W.T., Lurie E.A., Shabbir A., Holley B.M., Van Slooten P.R 2014 High Efficiency Centrifugal Compressor for Rotorcraft Applications NASA/CR-2014-218114. 2014.

21. Галеркин Ю., Солдатова К. Применение метода универсального моделирования для разработки этапов модели центробежного компрессора // Протоколы 8-й международной конференции по компрессорам и их системам. 2013. С. 477-487.

22. Van den Braembussche R. Centrifugal compressors: One dimensional design. (VKI Course Note No. 134), von Karman Institute, Sint-Genesius-Rode, Belgium. 1987.

23. Kim Y., Engeda A., Aungier R., Amineni N. A centrifugal compressor stage with wide flow range vaned diffusers and different inlet configurations. Proceedings of the Institution of Mechanical Engineers Part a-Journal of Power and Energy. 2002. 216 (A4). 307-320.

24. Wygant K., Bygrave J., Bosen W., Pelton R., Tutorial on the application and design of integrally geared compressors. Proceedings of the Asia Turbomachinery and Pump Symposium. 2016. DOl: https://doi.org/10.21423/R1N97X.

25. Al-Busaidi W., Pilidis P. A new method for reliable performance prediction of multi-stage industrial centrifugal compressors based on stage stacking technique: Part I - existing models evaluation. Applied Thermal Engineering. 2016. 98. 10-28.

26. Came P.M., Robinson C.J. Centrifugal compressor design. Proceedings of the Institution of Mechanical Engineers Part C-Journal of Mechanical Engineering Science. 1999. 213 (2). 139-155.

27. Dalbert P., Ribi B., Kmeci T., Casey M. Radial compressor design for industrial compressors. Proceedings of the Institution of Mechanical Engineers, Part C: Journal of Mechanical Engineering Science. 1999. 213 (1). 71-83.

28. Flaxington D., Swain E. Turbocharger aerodynamic design. Proceedings of the Institution of Mechanical Engineers, Part C: Journal of Mechanical Engineering Science. 1999. 213(1). 43-57.

29. Krain H. Review of centrifugal compressor's application and development. Journal of Turbomachinery-Transactions of the ASME. 2005.127 (1). $25-34$.

30. Грузков С.А. Электрооборудование летательных аппаратов: учебник для вузов. В двух томах. М.: МЭИ, 2005.

31. Акопов М.Г. Системы оборудования летательных аппаратов. М.: Машиностроение, 2005.

32. Барвинский А.П., Козлова Ф.Г. Электрооборудование самолетов, 1981. 
33. Cronin M.J. Design aspect of systems in all electric aircraft (SAE Techn. Pap. Ser.). 821436. D0I: https://doi.org/10.4271/821436.

○ Смагин Денис Игоревич (79637587781@yandex.ru ), Старостин Константин Игоревич (ki-star1969@yandex.ru ),

Савельев Роман Сергеевич (r_sr@inbox.ru ), Напреенко Константин Сергеевич (konaprko@yandex.ru ),

Васильев Николай Георгиевич (col.vasilie2012@уandex.ru ), Красавин Егор Эдуардович (krasavin.ieghor@mail.ru).

Журнал «Современная наука: актуальные проблемы теории и практики»

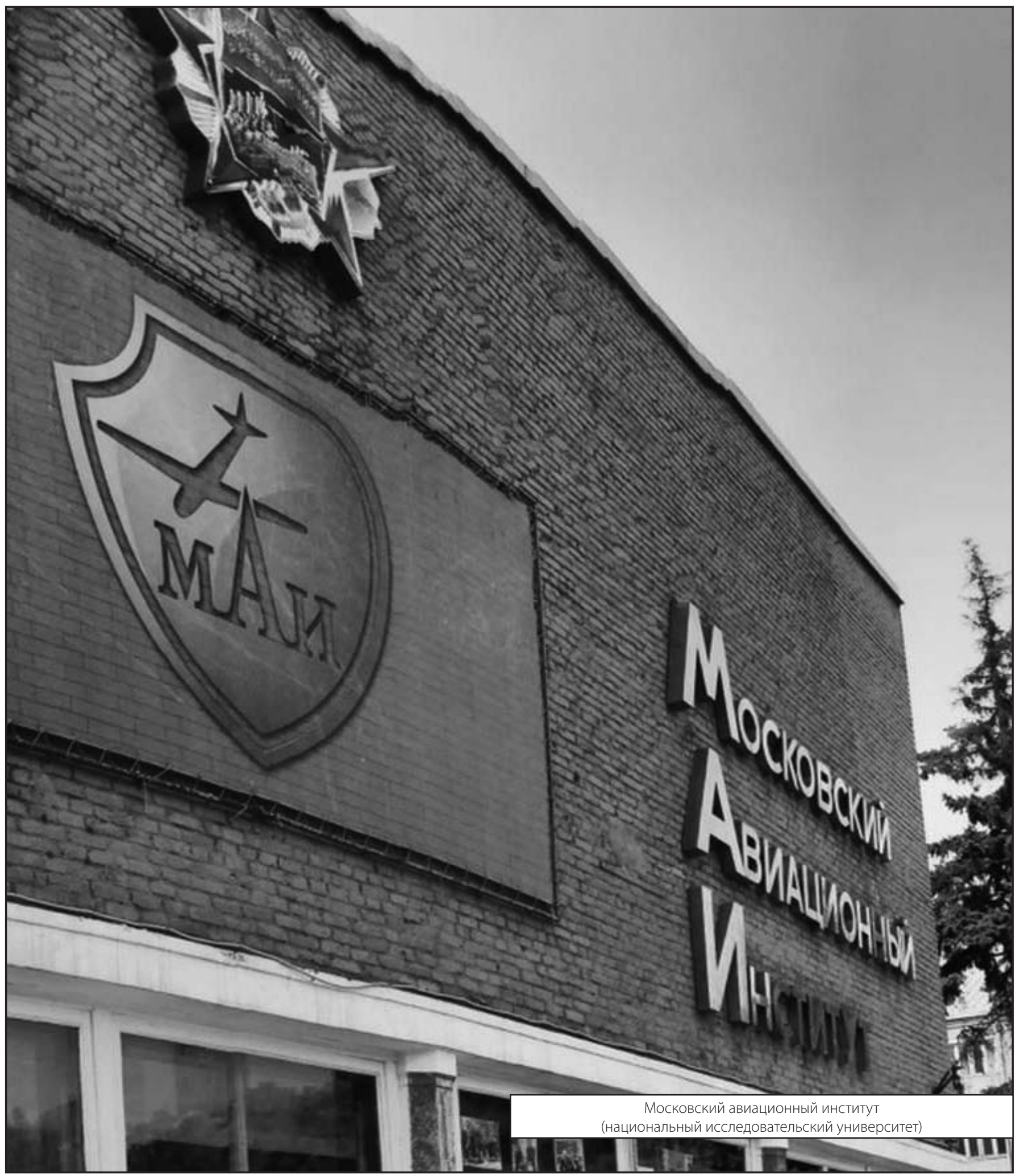

